\section{Ukraine will close reactors}

\section{Moscow}

THE report of the official government commission of inquiry into the recent fire at Chernobyl (see Nature 353, 690; 24 October 1991) has precipitated a decision by the Ukrainian parliament to close the remaining reactors on the Chernobyl site. The Ukraine is now wondering where its power will come from.

The commission, in a report that echoes the muddle associated with the nuclear accident in 1986, says that the immediate cause of this year's accident was an electrical short-circuit in a multiple-conductor cable linking the generator with the distribution plant some hundreds of metres away. According to the Chernobyl Information and International Contacts Office, damaged insulation was responsible.

The result of the short was inadvertently to cut in the high-voltage switch, making the generator function as an asynchronous motor. The resulting overload on the generator is said to have destroyed the sealing bearings, allowing hydrogen and turbine oil to escape into the machine room. The mixture ignited with a characteristic explosive sound, and two massive torches like gas burners heated up the metal frame of the generator, making it unfit for further use. The roof collapsed, leaving a 2,500-square-metre opening through which rain and snow now fall.

Not until the end of October, more than two weeks after the accident, was the machine room cleared of debris and preparations started for roof repairs. The total damage is estimated at several tens of millions of rubles. Initially, the Soviet Ministry for the Nuclear Industry assessed the accident on its eight-point scale as a Category 1 incident. Under pressure from the official inquiry, it is now ranked Category 2 . No accusations have been made against the personnel, still less the fire brigade. But it seems clear that the lesson of the Chernobyl accident in 1986 had not been learned. When the operators began to remove oil from the burning turbo generator, the standby tanks for emergency discharge were found to be filled with waste oil that should have been removed from the site, so that new oil had to be emptied onto the floor.

The commission says that the fire brigade acted bravely in extinguishing the flames in a matter of hours. Just as in April 1986, they had neither special machines, protective gear nor instruments.

The Ukrainian parliament's decision, last week, immediately to shut down the second reactor where the fire happened seems therefore inevitable. But the Ukraine has also decided that the first and third operational units must be shut down "in the shortest possible time and not later than 1993". The notorious fourth nuclear monster now lies in the sarcophagus but still represents, according to specialists, a dangerous source of radioactive contamination. Ways of finally neutralizing it have not yet been found. Construction of the fifth and sixth power units planned for the site has been halted, and will not be completed.

The overall cost of Chernobyl's assets is more than 1,000 million rubles. Another 500 million rubles went into the construction of Slavutich, the dormitory community of nearly 40,000 power workers $45 \mathrm{~km}$ from the nuclear project. The place is within the radioactive zone, and is likely now to become a ghost town. The prospects for the residents are grim. Finding houses and jobs elsewhere will be even more difficult now that the Ukrainian parliament has turned down the Council of Ministers' proposal to put on line power units at other nuclear facilities.

A further difficulty at Chernobyl is that nuclear installations of this size and
"Today is Wednesday, 23 October.

"For 23 days, the city has been without water, electricity, gas and telephone connections. There are 50,000 citizens and 10,000 refugees of the war within the stone city walls. They are under siege by air, land and sea. All the surroundings have been deliberately burned with phosphorus bombs. Hunger and disease now stalk a city dedicated to culture, the arts and sciences, and to the highest levels of education embodied in its unique Interuniversity Centre.

"The old city of Dubrovnik, catalogued by UNESCO as a World Heritage site, has today witnessed the cruel and disastrous shelling of its ancient centre. The main street, the Stradun or Placa, is devastated and ghostly. The broken glass is in my mind the broken vase of illusion in which we were living. We had been working for a world of responsibility, mutual understanding and support, a world without borders.

"Instead, shells fired by the Yugoslavian Navy have fallen on Lapad, on Gruz, on the hospital at Medarevo, on the Museum Rupe and the School of Music, on Ruder Boskovic street and on the old fortresses of Minceta, Revelin and Bokar. The whole area of the Ploce, from the old harbour to the Hotel Belvedere, has been bombed, as have been the villages of Srebreno, Mlini, Kupari and Plat. The nicest of them all, the town of Cavtat known as the Greek colony Epidaurus, has been seized by federal troops. sophistication have not previously been closed down and dismantled. A special scientific and technical programme and large sums of money are needed. The Ukrainian Supreme Soviet, fearing that it would not be able to handle the issues on its own, has appealed to the United $\mathrm{Na}$ tions and to governments of other countries for help.

The parliament must also decide how to make up the power deficit the closure of Chernobyl will create. In 1990, the Ukraine produced 3.7 million tonnes of oil, while importing 58.4 million tonnes from elsewhere in the union. Last month, only eight of the 15 ex-union republics signed the treaty creating an Economic Community, and the Ukraine was not among them. It is believed that this will impede access to oil from outside the Ukraine, but the well-fed Ukraine may have the means to barter with hungry Russia for oil.

Meanwhile, the Ukrainian Parliament has decided to make up for the power losses by emergency construction of a steam-gas facility.

Yuri Kanin

\title{
A letter from Dubrovnik
}

"During the week of 20 October, we had planned to hold the fourth scientific congress of the Croatian Biological Society at the Interuniversity Centre. We had planned topics in molecular biology, genetics, evolution, cancer, physiology and health, education in ecology and the timely efforts of the International Council on the Conservation of Nature. But our main topic was to have been the environmental problems of our sea, the Adriatic, to celebrate the centenary of research at the Rovinj Centre for Marine Research.

"We had been honoured by the num. ber of distinguished people from abroad who had accepted our invitation. We were happy to have scientists registered from Slovenia, Italy, Serbia, the United States, Bosnia, Montenegro and Macedonia.

"But now we have not been able to talk about science at all - not about the genetics and conservation of the Mediterranean monk seal, not about the bottlenose dolphins of the Adriatic, not about our plans for saving our sea. Instead, we are sending a desperate SOS on behalf of our potential hosts, who have been let down by Europe and the World. Can nothing be done to save our cultural heritage at Dubrovnik?"

This message is from Professor Drasko Serman of the Biology Department of the Medical School at the University of Zagreb, who is the current President of the Croatian Biological Society. 